Conclusions A data quality improvement initiative significantly improved accuracy of data used to monitor maternal progress of this $\mathrm{MNH}$ Collaborative in Ethiopia.

\section{FROM NO SHOW TO ARRIVED: USING MACHINE LEARNING TO BOLSTER PATIENT ATTENDANCE FOR RESIDENT CONTINUITY-CLINIC APPOINTMENTS}

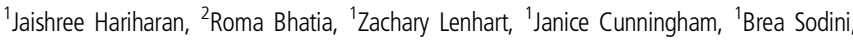
${ }^{1}$ Dang Tran, ${ }^{1}$ Oscar Marrequin, 'Gary Fischer. ${ }^{1}$ University of Pittsburgh Medical Center, USA; ${ }^{2}$ Beth Israel Deaconess Medical Center, USA

10.1136/bmjoq-2019-ihi.22
Background Resident continuity-clinic (RCC) is a crucial component of ambulatory training in primary care.The no-show rate (NSR) in a large academic center with 60 residents averaged 27\% in academic year (AY) 2018, despite an automated phone/text reminder system 3 days prior to appointment, resulting in fragmented care, reduced access and decreased learning opportunities for residents.

Objectives To determine whether telephone outreach targeting patients predicted to be at high-risk to no-show can reduce NSR for RCC appointments.

Methods A validated machine-learning prediction model developed by data scientists at UPMC for Primary care, generated a daily list of high-risk patients (i.e. $=20 \%$ risk to no-show).

Abstract 22 Table 1 Patient characteristics: resident clinic. Unique patients scheduled in AY 2019

\begin{tabular}{|c|c|c|}
$\begin{array}{l}\text { Pt Demographics } \\
\text { AY } 2019\end{array}$ & $\begin{array}{l}\text { Unique Scheduled } \\
\text { Patients (N/\%) }\end{array}$ & $\begin{array}{l}\text { No Shows (Unique } \\
\text { Patients) (N/\%) }\end{array}$ \\
\hline Unique patients & 6230 & $1532(25 \%)$ \\
\hline Age 18-39 Yrs & $2990(48 \%)$ & $710(46 \%)$ \\
\hline Age 40-64 & $2430(39 \%)$ & $693(44 \%)$ \\
\hline Age > 65 & $810(13 \%)$ & $157(10 \%)$ \\
\hline Gender & & $841(55 \%)$ \\
\hline Female & $3606(58 \%)$ & $691(45 \%)$ \\
\hline Male & $2624(42 \%)$ & $941(61 \%)$ \\
\hline Ethnicity/Race & & $466(30 \%)$ \\
\hline Black & $2618(42 \%)$ & \\
\hline White & $2817(45 \%)$ & $376(28 \%)$ \\
\hline Insurance & & $608(45 \%)$ \\
\hline Commercial & $2625(48 \%)$ & $287(21 \%)$ \\
\hline Medicaid & $1568(29 \%)$ & \\
\hline Medicare & $1093(20 \%)$ & \\
\hline
\end{tabular}

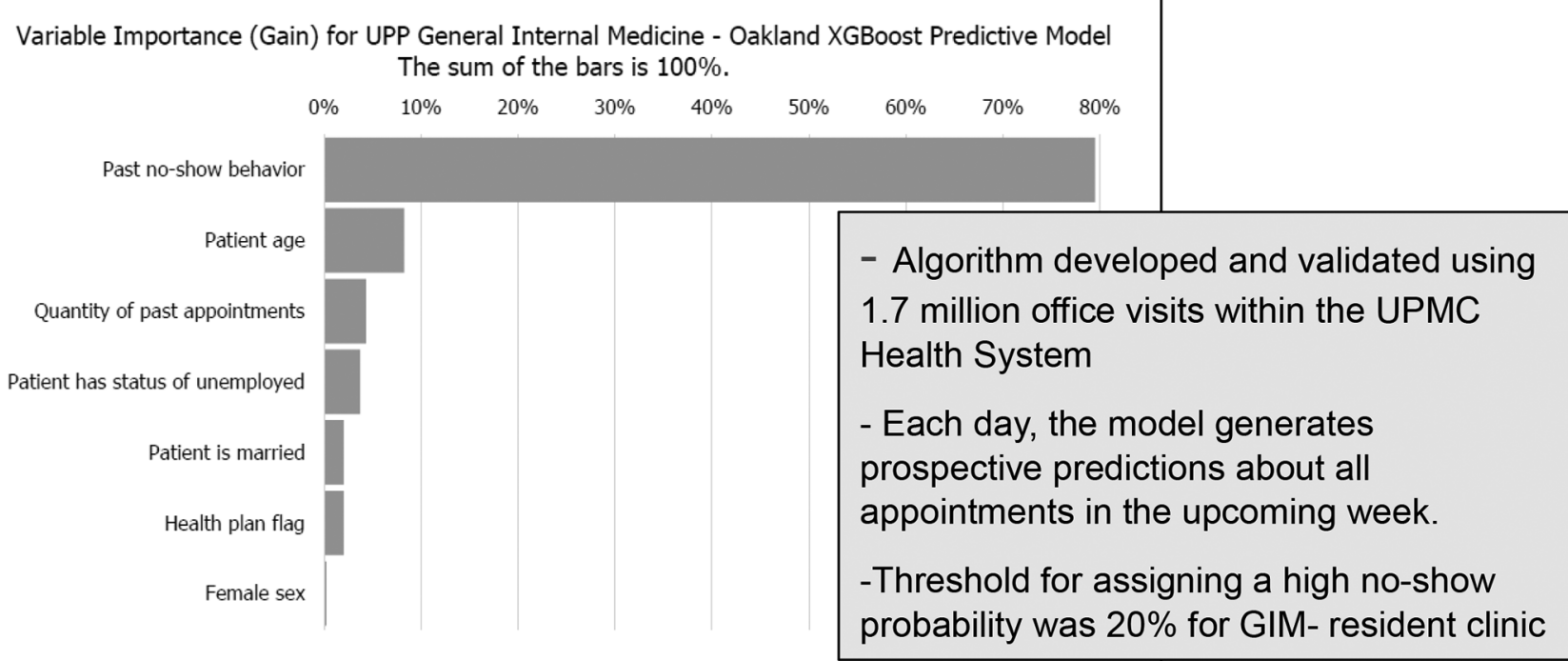

Abstract 22 Figure 1 Determinants of machine learning algorithm 


\begin{tabular}{|l|l|l|l|l|c|c|}
\hline Appointment Time & $\begin{array}{l}\text { Name of } \\
\text { Patient }\end{array}$ & $\begin{array}{l}\text { Mobile Tel } \\
\#\end{array}$ & $\begin{array}{l}\text { Home } \\
\#\end{array}$ & Provider Name & $\begin{array}{l}\text { Date of } \\
\text { Birth }\end{array}$ & $\begin{array}{l}\text { The } \\
\text { Prediction* }\end{array}$ \\
\hline Wed 4/17/2019 12:45 PM & & & & FLESHNER VITAL & & $30.8 \%$ \\
\hline Wed 4/17/2019 01:45 PM & & & & DOE JANE & & $27.5 \%$ \\
\hline Wed 4/17/2019 02:15 PM & & & & ORLANDO JOE & & $25.9 \%$ \\
\hline Wed 4/17/2019 02:15 PM & & & & PITTSBURGH STEELER & & $40.4 \%$ \\
\hline Wed 4/17/2019 02:45 PM & & & & HURRICAN DORIAN & & $27.9 \%$ \\
\hline Wed 4/17/2019 03:45 PM & & & & CHICAGO BEAR & & $52.7 \%$ \\
\hline
\end{tabular}

Abstract 22 Figure 2 Sample daily report

\section{Phone Call Outcomes $(n=2,046)$}
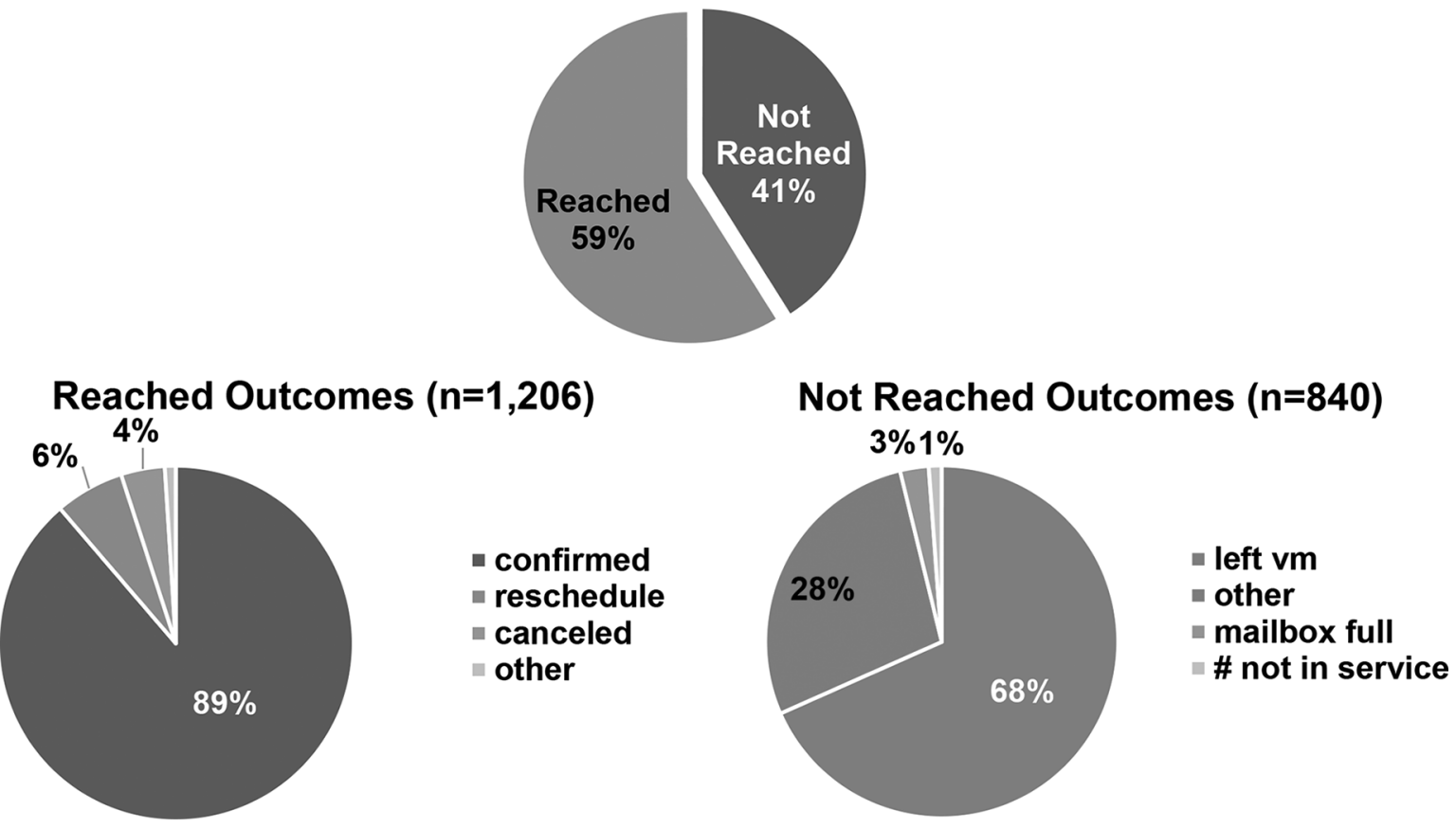

Abstract 22 Figure 3 Outcome of Phone calls: Reached or Not reached. If reached, appointment confirmed, canceled, rescheduled, or other (language barriers/hospital admissions). If not reached, other includes: no answer/ no voice mail set up, phone number wrong in chart, \& no active phone

\begin{tabular}{|c|c|c|c|c|c|}
\hline Resident Clinic Appts & AY 18 (N) & $\begin{array}{l}\text { NSR (AY 18) } \\
\% \pm 95 \% \mathrm{Cl}\end{array}$ & FY19 (N) & $\begin{array}{l}\text { NSR (AY 19) } \\
\% \pm 95 \% \text { CI }\end{array}$ & $\begin{array}{l}\text { Change }(\cdot 2) \\
N(\%)\end{array}$ \\
\hline $\begin{array}{l}\text { Total Scheduled Visits } \\
\text { (no-shows+ completed) }\end{array}$ & 9221 & & 9140 & & -89 \\
\hline No-Show Visits & 2482 & $\begin{array}{l}27 \%[25.7 \% \\
\text { to } 28.4 \%]\end{array}$ & 2118 & $\begin{array}{l}23 \%[21.6 \% \text { to } \\
25.0 \%]\end{array}$ & $\begin{array}{l}-364(4 \%) \\
(p<0.01)^{*}\end{array}$ \\
\hline Completed Visits (\%) & 6739 & $\begin{array}{l}73 \%[71.5 \% \\
\text { to } 74.2 \%]\end{array}$ & 7022 & $\begin{array}{l}77 \%[75.0 \% \text { to } \\
78.3 \%]\end{array}$ & +283 \\
\hline $\begin{array}{l}\text { "All" Visits (no-show+ } \\
\text { completed+ canceled") }\end{array}$ & 11,603 & & 12,098 & & $+495(4 \%)$ \\
\hline Canceled Visits** & 2382 & $21 \%$ & 2967 & $25 \%$ & $+585(4 \%)$ \\
\hline RVU's & 8941.8 & & 9658.8 & & +717 \\
\hline
\end{tabular}

Abstract 22 Figure 4 Analysis of Resident clinic Appointments: AY 2018 and AY 2018. No-show rate (NSR) calculated against completed + noshows. * P value using Chi-Square test. ${ }^{* *}$ Canceled visits include same day cancellation and cancelled rate calculated against 'All' visits. \pm \pm \pm 
Starting Oct 2018, these patients received a phone-call reminder from a clinical staff, 48 hours prior to their scheduled appointment. The outcomes of the call recorded were confirmed, cancelled, rescheduled, voicemail, not reached. Monthly NSR was tracked from July 2017 through June 2019 and analyzed using control charts.

\begin{tabular}{|l|l|l|l|l|}
\hline Revenue Generated & $\$ 359,177$ & $\$ 399,533$ \\
\hline
\end{tabular}

P Chart- No Show Data 2017-2019

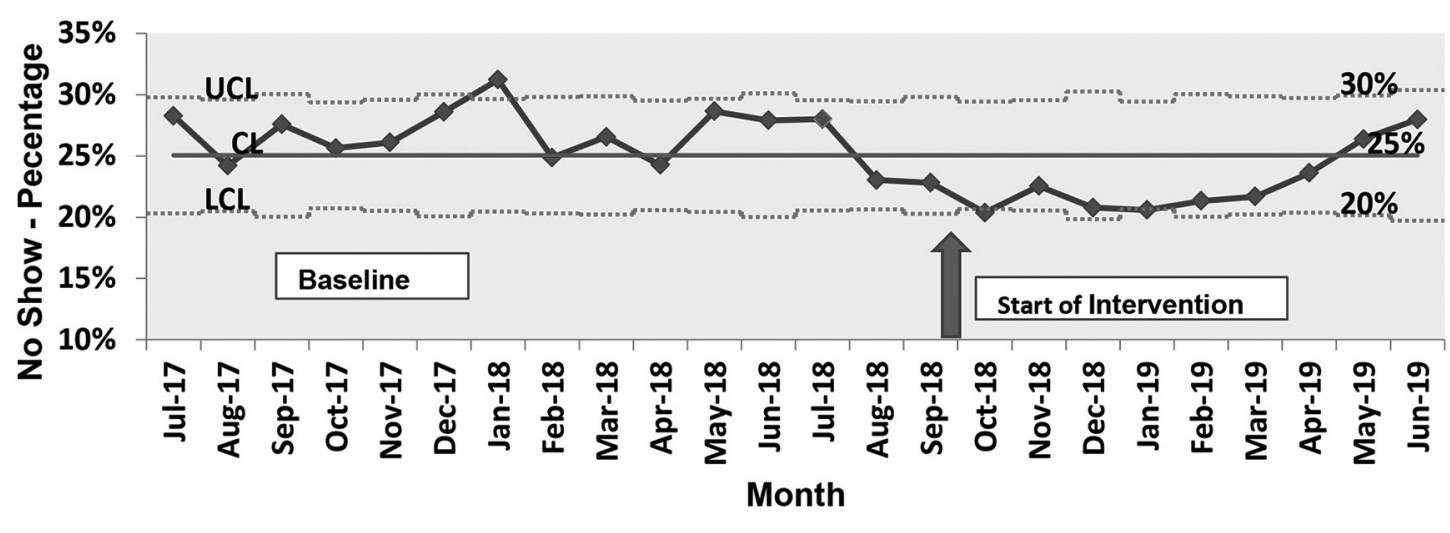

No Show rate: Pre (AY 18) \& Post Intervention (AY-19)

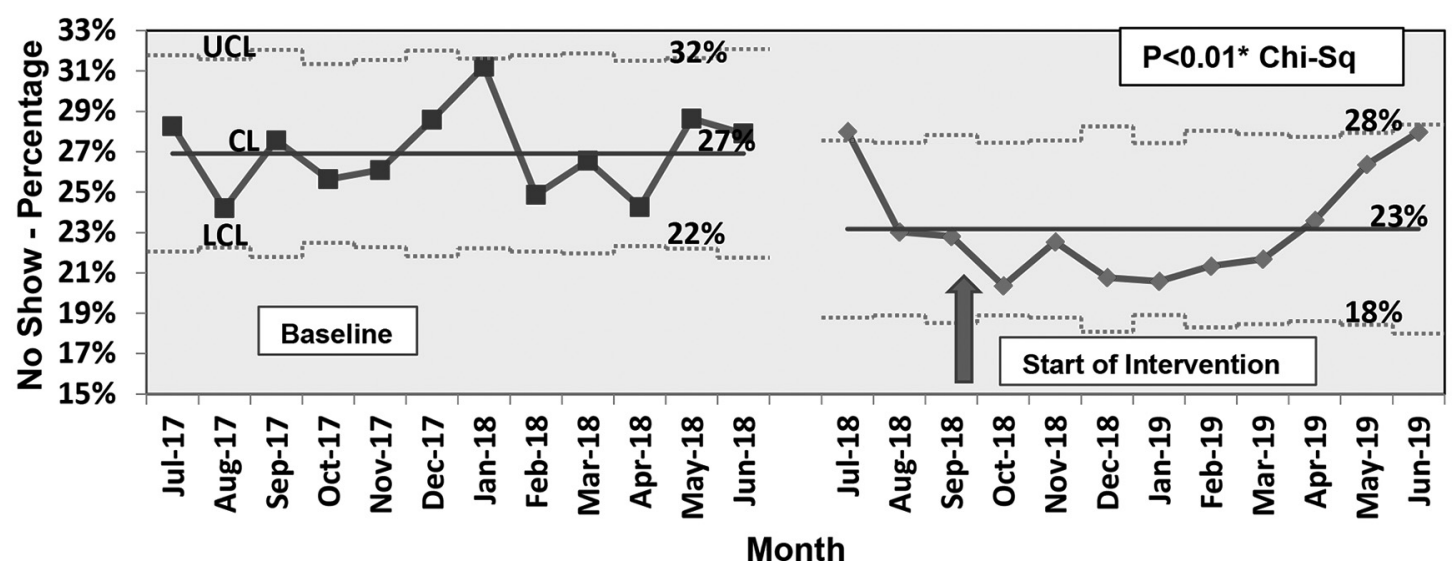

Abstract 22 Figure 5 (A) Control Chart (P chart): Resident Clinic No-Show data from July 2017-June 2019. (B) Control Chart Showing: No-show rate, pre (AY 2018) and post intervention (AY 2019). Intervention start date -Oct 2018

Run Chart: Model Predicted No Show,Pts Reached( N\&\%) and No- Show Rate

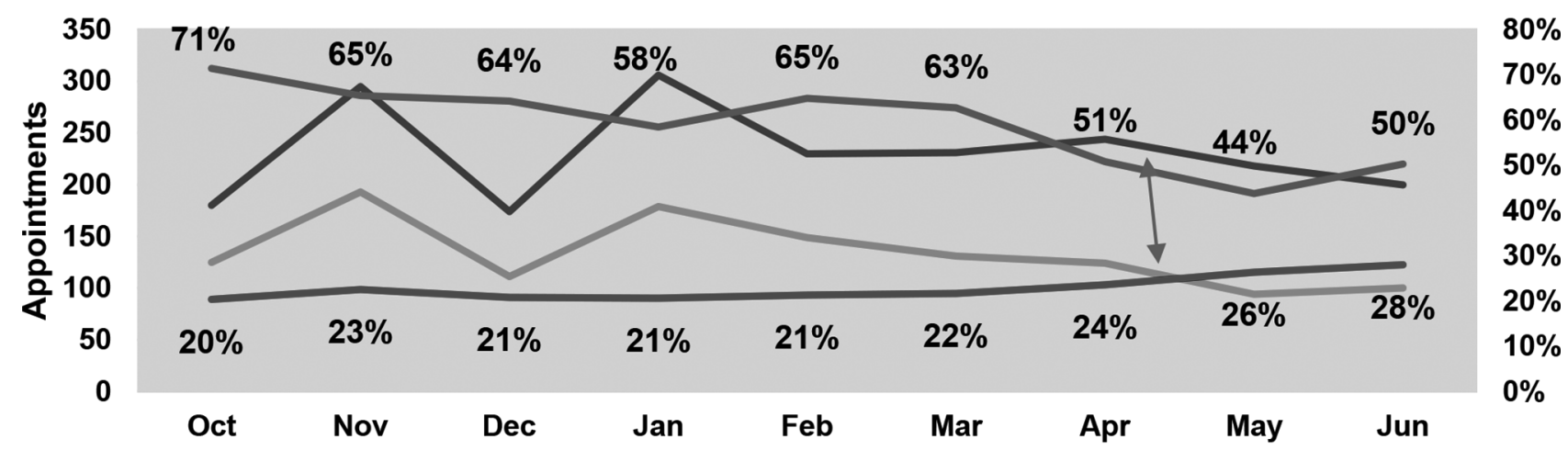

Model Predicted No-Show $\longrightarrow$ Patients Reached $=$ Pts Reached No Show Rate

Abstract 22 Figure 6 Run Chart (Oct 18-June 19): Model Predicted No Shows (N), patients reached (N\&\%), monthly NSR\%. Apr->Jun; lower percentage of patients reached and higher no-show rates 
Results Fifty-nine percent (1206/2046) of targeted patients were reached. Of those $89 \%$ confirmed and $10 \%$ canceled or rescheduled their appointment. The overall no-show rate for RCC appointments in (AY) 2019 decreased to 23\%, $\mathrm{p}<0.01,95 \%$ CI $[21.6 \%$ to $25.0 \%]$, resulting in additional 283 completed visits and $\$ 40,000$ in revenue. Higher no-show rates correlated with lower percentage of patients reached. Patients on government-assisted insurance (76\%) and AfricanAmericans (61\%) had higher no-shows and a major barrier was transportation.

Conclusions To our knowledge this is the first study showing that targeted phone outreach for high-risk patients can decrease NSR for RCC appointments, augmenting resident learning opportunities and revenue.

\section{OUTCOMES OF CREATING AN AUTOMATED REPEAT LACTATE RULE IN SEPSIS PATIENTS WITH LACTATE LEVELS $>2$}

Mary Ayad, Siddharth Karanth, Michelle Narat, Katharine Luther, Bela Patel. UT Health MGovern Medical School, USA

\subsection{6/bmjoq-2019-ihi.23}

Background Sepsis is a complex disease process that possesses a socioeconomic burden in the U.S. ${ }^{1}$ Serum lactate and lactate clearance form an important component of the sepsis resuscitation bundle ${ }^{2}$ and high levels correlate with worse outcomes. $^{3} 45$ Previous studies emphasized the importance of utilizing lactate monitoring to guide resuscitation to improve mortality. ${ }^{6} 7$

Objectives We aimed to enhance lactate monitoring and lactate guided resuscitation in sepsis patients with lactate levels $\geq 2$ $\mathrm{mmol} / \mathrm{L}$ in order to improve outcomes.

Methods An EMR automated Q2 lactate repeat orders for sepsis patients who have an initial lactate level $\geq 2 \mathrm{mmol} / \mathrm{L}$ was implemented. Lactate dashboards showing all patient-level lactate values during initial resuscitation was incorporated into Hospital Sepsis Committee Multi-Disciplinary meetings.

Results We included 1774 adult sepsis patients admitted from the ED to MICU from October 2014 to September 2018 who had an initial lactate level $\geq 2 \mathrm{mmol} / \mathrm{L}$. We aimed to compare the median time from ED arrival to lactate reduction to $<2 \mathrm{mmol} / \mathrm{L}$, median time from 1 st elevated lactate result to lactate $<2 \mathrm{mmol} / \mathrm{L}$ and the median length of stay (LOS). Post-intervention, the time from ED arrival to lactate $<2 \mathrm{mmol} / \mathrm{L}$ for those patients with an elevated lactate significantly reduced by 10.56 hours and the time from first elevated lactate to lactate $<2 \mathrm{mmol} / \mathrm{L}$ significantly reduced by 9.51 hours. LOS reduced by 3 days post intervention.

Conclusions Implementing an automated repeat lactate order for sepsis patients along with a multi-disciplinary review of dashboards resulted in an improvement in lactate clearance and a reduction in LOS. Further studies are needed to investigate this finding.

\section{QUALITY IMPROVEMENT PROJECT TO INCREASE COMMUNITY TB DETECTION IN WACHA PRIMARY HOSPITAL}

${ }^{1}$ Biniam Teshome, ${ }^{2}$ Nebiyou Wendwessen. 'Wacha Primary Hospital, Ethiopia; ${ }^{2} \mid H I$, Ethiopia

\subsection{6/bmjoq-2019-ihi.24}

Background Wacah primary hospital is located in Ethiopia 513 $\mathrm{km}$ away from the capital Tuberculosis is a major public health problem posing significant deleterious health impacts by affecting the productive segment of the population and resulting serious burden to the health system and exploiting the individual's/household economy. Community TB detection plays crucial role to control its transmission in the community but our hospitals community TB detection rate is at $19 \%$.

Objectives To increase our community $\mathrm{TB}$ detection rate from a baseline of $19 \%$ to $50 \%$ by the end of April 2019 .

Methods 1. Refreshment course for HEW (health extension workers) were given 2. Sputum smear preparation: One big problem identified was patients were refusing to be referred because of the distance and lack of transport. So our change idea was to train HEW on how to prepare sputum smear slides for suspected patients, after the slides were prepared they bring it to the hospital. If patient is positive he will be recalled from the community to get treatment. 3. Flyers about sign and symptom of TB were prepared and deployed for the general public 4. Health education on $\mathrm{Tb}$ was given by nurses

Community TB detection in wacha primary hospital

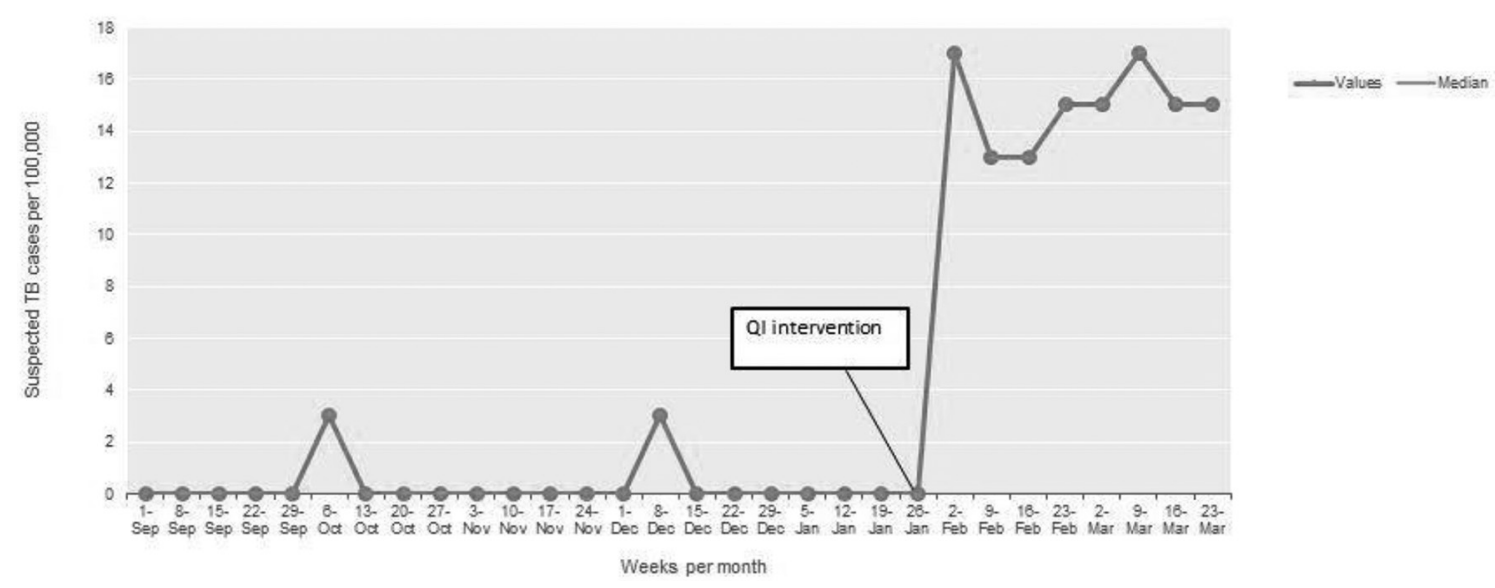

